B3

J. bio-sci. 16: 29-34, 2008

ISSN 1023-8654

http://www.banglajol.info/index.php/JBS/index

\title{
ENZYME ACTIVITIES AND DEGRADATION OF NUTRIENTS IN CHICKPEA (CICER ARIETINUM L.) SEEDS DURING GERMINATION
}

\author{
M S Rahman, N K Sana*, M M Hasan, M E Huque ${ }^{1}$ and R K Shaha \\ Department of Biochemistry and Molecular Biology, University of Rajshahi, Rajshahi-6205, Bangladesh
}

\begin{abstract}
Enzyme activities and degradation of seed storage substances were investigated in BARI-1, BARI-2 and BARI-3 varieties of chickpea (Cicer arietinum L.) seed at different germinating periods. Among the varieties, the highest amylase activity was found in BARI-2 and lowest in BARI-3 during germination at 45 hours in water. The maximum activity of invertase was found in BARI-2 and minimum in BARI-1 at 72 hours of germination. Lipase activity was highest in BARI-2 and lowest in BARI-1. The highest protease activity was found in BARI-2 and lowest in BARI-3. The amount of total protein and water-soluble protein were found to be highest in BARI-1 and BARI-3, respectively. During light germination, carbohydrate depletion starts after initial imbibitions, and was completed in 120-144 hours. The variety BARI-1 was found to contain the highest amount of free sugar while BARI-3 had the lowest amount. BARI-2 was found to contain highest amount of reducing sugar and BARI-1 contained the lowest amount. The highest amount of starch was found in BARI-3 and lowest in BARI-1. The starch content in chickpea seed decreased gradually during germination. Among the varieties, BARI-1 was found to contain the highest amount of lipid while BARI-3 contained the lowest amount. The seed storage substances were found to decrease gradually with the increase of germination time. The results indicate that degradation of reserve seed nutrients accelerate the development of seedling growth during germination.
\end{abstract}

Key words: Chickpea (Cicer arietinum L.) seed, Carbohydrate, Protein, Lipid, Hydrolytic Enzymes.

\section{Introduction}

Chickpea (Cicer arietinum L.) is an important pulse crop in Bangladesh occupying second position after lentil. It is the world's third most important pulse crop. Bangladesh and India produce about $75 \%$ of the world's supply (Ignacimuthu and Prakash 2006). It is grown in over 40 countries representing all the continents of which over $95 \%$ of the area. Seeds of chickpea are valuable source of protein (Gupta et al. 2007). It is also an important source of carbohydrates, B-group vitamins, and certain minerals, particularly to the populations of developing nation and it is mostly consumed as dhal, whole seeds, and several types of traditional, fermented, deep fried, sweetened, and puffed products (Chavan et al. 1986). There was no difference in the essential amino acid contents and in chemical scores of desi and kabuli (Viveros et al. 2001) chickpeas. During germination the seed storage substances used up for seedling growth and some hydrolytic enzymes such as amylase, invertase, protease and lipase are activated. Chickpea contains insoluble and soluble fiber: the former promotes regular bowel movements, so helping to guard against constipation, as well as possibly lessening the risk of cancers of the colon and rectum; the latter has been connected with lowering blood cholesterol levels, thereby lessening the risk of heart disease and stroke (Geervani 1991). It is mainly used for human consumption and only a small proportion as feed. Chickpeas are used for making various delicious food items such as butter substitute, sprouting, salads, soups and stews. It is also known for its use in herbal medicine and cosmetics. Some researchers studied amino acids content (Khan et al.1995, Gupta et

\footnotetext{
*Corresponding author: e-mail: nksana2003@yahoo.com
} 
al. 2007), its chemical composition (Viveros et al. 2001, El-Adawy 2002, Suhasini and Malleshi 2003), carbohydrates (Hawkins and Johnson 2005) and mineral content (Nestares et al. 1999) in ungerminated chickpea seeds.

There have been very few reports on the enzyme activities and degradation of seed storage substances particularly on germinated chickpea seeds. The aim of this report is to study the enzyme activities and degradation of nutrients in different varieties of chickpea at different germinating periods.

\section{Materials and Methods}

Material: The three varieties BARI-1, BARI-2 and BARI-3 of chickpea seeds (Cicer arietinum L.) were collected from Bangladesh Agriculture Research Institute (BARI), Iswardi, Pabna; in the month of OctoberNovember. After collection, the seeds were cleaned, dried in the sunlight and kept in a polyethylene bag and stored separately in deep freeze $\left(-10^{\circ} \mathrm{C}\right)$ for biochemical analysis. Glucose, BSA, Dinitrosalicylic acid (DNS) and Sodium tungstate were purchased from Sigma Chemicals Ltd., USA. Chloroform, Ethanol and Trichloro acetic acid (TCA) were purchased from Pharmacia Fine Chemicals Ltd., Sweden. All other chemicals were of analytical grade and were used without further purification.

Germination of seed: Good and mature seeds of chickpea were sorted out for germination. The sorted seeds were soaked in distilled water within a glass beaker with potassium permanganate for six hours. Potassium permanganate was used for avoiding the growth of microorganism on seed surfaces during germination. The soaked seeds were then taken out from water and scattered on a fiter paper, placed on a plastic tray containing little amount of distilled water. The tray was then placed in a lighted room at $22^{\circ} \mathrm{C}$ for $24,36,40,45,72,96,120$ and 144 hours including soaking time. The germinated seeds at different hours were separated from seedling, rinsed with distilled water and stored separately in a deep freeze $\left(-10^{\circ} \mathrm{C}\right)$ for analysis.

Preparation of the crude extract: 100 grams of germinated seeds were crushed in a mortar with a pestle and then suspended in $40 \mathrm{ml}$ of $30 \%$ acetone. After occasional gentle stirring for 3 hours at $4^{\circ} \mathrm{C}$ the suspension was filtered through double layer of muslin cloth. The filtrate was collected and centrifuged in a refrigerated centrifuge at $5500 \mathrm{rpm}$ for 15 minutes at $4^{\circ} \mathrm{C}$. The supernatant was used as "crude extract".

Ammonium sulphate fractionation: The crude extract was saturated to $30-50 \%$ by the addition of solid ammonium sulphate under constant and gentle stirring at $4^{\circ} \mathrm{C}$. The resulting precipitate was collected by centrifugation, dissolved in minimum volume of pre-cold distilled water and dialyzed against distilled water for 24 hours at $4^{\circ} \mathrm{C}$. The dialyzed solution was then centrifuged in a refrigerated centrifuge machine at $5500 \mathrm{rpm}$ for 15 minutes to remove the insoluble materials. The clear supernatant thus obtained was designated as "crude enzyme solution".

Measurement of enzyme activity: The amylase activity was assayed following the method as described by Jayaraman (1985), the invertase activity was assayed following the method of Mahadevan and Sridhar (1982), the protease activity was measured following the method of Kunitz (1947) and the lipase activity was assayed essentially as described by Sugihara et al. (1990).

Degradation of nutrients during germination of chickpea seed: Total protein content of chickpea seeds was determined by the method of Micro-Kjeldahl (Wong 1923) and the water-soluble protein content by the method of Lowry et al. (1951). Free sugar content of chickpea seeds was determined calorimetrically by the anthrone method (Morse 1947). Reducing sugar content of chickpea seeds was estimated by DNS (Dinitrosalicylic acid) method (Miller 1972). The starch content of chickpea seeds was determined by the anthrone method (Morse 1947, Jayaraman 1985) and lipid content of chickpea seeds was determined by the method of Bligh and Dyer (1959). 


\section{Results}

The activities of different enzymes in the three varieties of chickpea seeds are shown in Table 1. Activity of amylase in the three varieties of chickpea was determined during various germinating periods. The activities varied from 9.85 to 40.25 unit/ml. After 45 hours germination, the variety BARI-2 and BARI-3 showed the highest $(40.25$ unit/ml) and the lowest $(9.85 \mathrm{unit} / \mathrm{ml})$ amount of amylase activities, respectively. During germinating stage, invertase activities in the three different varieties ranged from 2.30 to $7.21 \mathrm{unit} / \mathrm{ml}$. The highest invertase activity was found in BARl-2 (7.32 unit/ml) and the lowest in BARI-1 (5.32 unit/ml) at 72 hours. At 40 hours of germination, BARI-2 showed the highest protease activities $(38.45 \mathrm{unit} / \mathrm{ml})$ while lowest in BARI-3 (37.01 unit/ml) variety. The lipase activities in different varieties varied from 2.72 to $11.32 \mathrm{unit} / \mathrm{ml}$. Among the varieties, BARI-2 and BARI-1 showed the highest (11.32 unit/ml) and the lowest (9.55 unit/ml) lipase activities at 40 hours, respectively.

Total protein and water-soluble protein contents of the germinated chickpea seeds at different periods of germination are presented in Table 2. The protein content determined by the Micro Kjeldahl method showed considerably higher amount than that given by Lowry method.

Free sugar content at different periods of germination of chickpea seeds is represented in Table 2. As shown in table, the free sugar content in the three varieties (BARI-1, BARI-2 and BARI-3) were found to be $5.90 \%$, $5.65 \%$ and $5.45 \%$ respectively. During germination up to 144 hours, free sugar degradation was found to be regular in intact chickpea seeds.

The results about the degradation of storage reducing sugar are shown in Table 2 . The reducing sugar contents in BARI-1, BARI-2 and BARI-3 were found to be $0.40 \%, 0.43 \%$ and $0.41 \%$ respectively. During germination up to 144 hours reducing, sugar was found to be regularly degraded to $0.05 \%, 0.10 \%$ and $0.05 \%$, respectively.

Degradation of starch during different periods of germination of chickpea seeds is represented in Table 2. It was observed that BARI-1, BARI-2 and BARI-3 contained $56.00 \%, 56.04 \%$ and $56.12 \%$ starch, respectively. The starch contents in chickpea seeds were found to decrease gradually to $2.11 \%, 2.09 \%$ and $2.21 \%$ respectively during germination at 144 hours.

Amount of lipid at different periods of germination was determined by solvent extract process and is shown in Table 2. The result shows that the chickpea seeds contained $5.00 \%, 4.96 \%$ and $4.90 \%$ lipid respectively. Chickpea seeds lipid was found to be $0.17 \%, 0.11 \%$ and $0.10 \%$ respectively at 144 hours during germination in water.

Table 1. Activities of amylase, invertase, protease and lipase in three varieties of chickpea seed.

\begin{tabular}{cccccc}
\hline \multirow{2}{*}{ Varieties } & $\begin{array}{c}\text { Germinating time } \\
\text { hours }\end{array}$ & Amylase & Activity of enzymes (Units/ml) \\
\cline { 2 - 5 } & 36 & $9.95 \pm 0.03$ & $2.55 \pm 0.02$ & $20.04 \pm 0.01$ & $5.35 \pm 0.03$ \\
& 40 & $31.52 \pm 0.01$ & $3.85 \pm 0.01$ & $37.95 \pm 0.02$ & $9.55 \pm 0.03$ \\
BARI-1 & 45 & $38.69 \pm 0.02$ & $4.08 \pm 0.01$ & $32.51 \pm 0.02$ & $5.19 \pm 0.01$ \\
& 72 & $19.82 \pm 0.04$ & $5.32 \pm 0.02$ & $27.45 \pm 0.03$ & $4.35 \pm 0.02$ \\
& 96 & $14.45 \pm 0.03$ & $3.15 \pm 0.03$ & $23.35 \pm 0.02$ & $3.85 \pm 0.03$ \\
& 120 & $11.23 \pm 0.01$ & $2.30 \pm 0.02$ & $21.02 \pm 0.01$ & $2.72 \pm 0.02$ \\
\hline BARI-2 & 36 & $10.04 \pm 0.02$ & $2.85 \pm 0.01$ & $21.15 \pm 0.01$ & $5.92 \pm 0.02$ \\
& 40 & $32.85 \pm 0.03$ & $4.15 \pm 0.02$ & $38.45 \pm 0.04$ & $11.32 \pm 0.02$ \\
& 45 & $40.25 \pm 0.01$ & $5.10 \pm 0.01$ & $33.00 \pm 0.03$ & $6.94 \pm 0.01$ \\
& 72 & $21.05 \pm 0.01$ & $7.21 \pm 0.02$ & $28.25 \pm 0.02$ & $5.75 \pm 0.03$ \\
& 96 & $15.35 \pm 0.02$ & $3.45 \pm 0.03$ & $23.35 \pm 0.03$ & $4.85 \pm 0.01$ \\
& 120 & $11.88 \pm 0.05$ & $3.01 \pm 0.01$ & $20.71 \pm 0.01$ & $4.02 \pm 0.02$ \\
\hline BARI-3 & 36 & $9.85 \pm 0.01$ & $2.52 \pm 0.01$ & $20.01 \pm 0.02$ & $5.45 \pm 0.01$ \\
& 40 & $30.65 \pm 0.02$ & $3.95 \pm 0.03$ & $37.01 \pm 0.02$ & $9.76 \pm 0.02$ \\
& 45 & $37.11 \pm 0.03$ & $4.09 \pm 0.02$ & $31.86 \pm 0.02$ & $6.27 \pm 0.03$ \\
& 72 & $19.18 \pm 0.02$ & $6.19 \pm 0.02$ & $27.35 \pm 0.03$ & $4.65 \pm 0.01$ \\
& 96 & $13.95 \pm 0.04$ & $3.55 \pm 0.03$ & $22.25 \pm 0.01$ & $4.01 \pm 0.02$ \\
\hline
\end{tabular}


Table 2. Protein, sugar, starch and lipid content of chickpea seed at different periods of germination.

\begin{tabular}{lccccccc}
\hline \multirow{2}{*}{ Nutrients } & \multirow{2}{*}{ Varieties } & \multicolumn{7}{c}{ Protein $(\%)$ at different hours $(\mathrm{h})$} \\
\cline { 3 - 7 } Total protein & $0(\mathrm{~h})$ & $48(\mathrm{~h})$ & $72(\mathrm{~h})$ & $96(\mathrm{~h})$ & $120(\mathrm{~h})$ & $144(\mathrm{~h})$ \\
& BARI-1 & $22.51 \pm 0.01$ & $18.80 \pm 0.01$ & $12.09 \pm 0.02$ & $8.25 \pm 0.03$ & $5.40 \pm 0.01$ & $4.30 \pm 0.01$ \\
& BARI-2 & $22.05 \pm 0.01$ & $18.72 \pm 0.02$ & $12.95 \pm 0.01$ & $8.65 \pm 0.01$ & $5.61 \pm 0.01$ & $4.45 \pm 0.01$ \\
& BARI-3 & $22.11 \pm 0.02$ & $18.87 \pm 0.01$ & $12.62 \pm 0.02$ & $8.54 \pm 0.01$ & $5.36 \pm 0.01$ & $4.19 \pm 0.01$ \\
\hline \multirow{2}{*}{ Water soluble } & BARI-1 & $15.55 \pm 0.02$ & $12.23 \pm 0.01$ & $8.01 \pm 0.02$ & $5.68 \pm 0.03$ & $3.90 \pm 0.04$ & $2.09 \pm 0.03$ \\
protein & BARI-2 & $15.61 \pm 0.01$ & $12.95 \pm 0.01$ & $8.26 \pm 0.02$ & $5.40 \pm 0.04$ & $4.01 \pm 0.02$ & $2.26 \pm 0.03$ \\
& BARI-3 & $15.68 \pm 0.02$ & $12.39 \pm 0.01$ & $8.21 \pm 0.03$ & $5.72 \pm 0.01$ & $3.09 \pm 0.01$ & $2.17 \pm 0.02$ \\
\hline \multirow{3}{*}{ Free sugar } & BARI-1 & $5.90 \pm 0.02$ & $4.52 \pm 0.01$ & $3.19 \pm 0.05$ & $2.00 \pm 0.01$ & $1.65 \pm 0.03$ & $0.99 \pm 0.01$ \\
& BARI-2 & $5.65 \pm 0.04$ & $4.45 \pm 0.01$ & $3.15 \pm 0.01$ & $1.85 \pm 0.01$ & $1.20 \pm 0.01$ & $0.94 \pm 0.02$ \\
& BARI-3 & $5.45 \pm 0.01$ & $4.36 \pm 0.02$ & $3.06 \pm 0.02$ & $1.65 \pm 0.01$ & $1.05 \pm 0.02$ & $0.87 \pm 0.01$ \\
\hline \multirow{2}{*}{ Reducing } & BARI-1 & $0.40 \pm 0.01$ & $0.35 \pm 0.02$ & $0.24 \pm 0.01$ & $0.14 \pm 0.01$ & $0.11 \pm 0.01$ & $0.05 \pm 0.01$ \\
sugar & BARI-2 & $0.43 \pm 0.01$ & $0.38 \pm 0.01$ & $0.29 \pm 0.01$ & $0.19 \pm 0.01$ & $0.16 \pm 0.01$ & $0.10 \pm 0.01$ \\
& BARI-3 & $0.41 \pm 0.01$ & $0.36 \pm 0.01$ & $0.25 \pm 0.02$ & $0.15 \pm 0.01$ & $0.11 \pm 0.02$ & $0.05 \pm 0.01$ \\
\hline \multirow{3}{*}{ Starch } & BARI-1 & $56.00 \pm 0.02$ & $50.44 \pm 0.01$ & $40.00 \pm 0.02$ & $17.41 \pm 0.01$ & $9.32 \pm 0.02$ & $2.11 \pm 0.02$ \\
& BARI-2 & $56.04 \pm 0.04$ & $50.50 \pm 0.01$ & $40.23 \pm 0.01$ & $17.43 \pm 0.01$ & $9.29 \pm 0.03$ & $2.09 \pm 0.01$ \\
& BARI-3 & $56.12 \pm 0.03$ & $50.65 \pm 0.03$ & $40.29 \pm 0.02$ & $17.50 \pm 0.01$ & $9.39 \pm 0.03$ & $2.21 \pm 0.01$ \\
\hline \multirow{2}{*}{ Lipid } & BARI-1 & $5.00 \pm 0.01$ & $4.17 \pm 0.03$ & $3.37 \pm 0.01$ & $2.13 \pm 0.01$ & $0.98 \pm 0.02$ & $0.17 \pm 0.01$ \\
& BARI-2 & $4.96 \pm 0.01$ & $4.09 \pm 0.02$ & $3.28 \pm 0.01$ & $2.17 \pm 0.01$ & $0.98 \pm 0.04$ & $0.11 \pm 0.01$ \\
& BARI-3 & $4.90 \pm 0.02$ & $4.06 \pm 0.02$ & $3.31 \pm 0.02$ & $2.14 \pm 0.01$ & $0.90 \pm 0.01$ & $0.10 \pm 0.01$ \\
\hline
\end{tabular}

\section{Discussion}

Amylase and invertase play a major role in carbohydrate metabolism in several plant tissues (WHO 1985) and starch is the major component of most of the world's crop yield and the degradation of starch is essential in the germination of these plants (Yamasaki 2003). Starch degradation in seeds requires the action of $\alpha$ and $\beta$ - amylase. The amylase activities were found to be highest in BARI-2 and lowest in BARI- 3 at 45 hours of germination. It was observed that amylase activity increased considerably during germination. The finding is in good agreement with those reported by Evans et al. (1997) and Sopanen and Lauriere (1989).

Invertase, which hydrolyzes sucrose into glucose and fructose, occurs in many plants and microorganisms. The expression and distribution of plant invertases has been especially well documented, because these are considered to play an important role in sugar metabolism (Kastle and Clark 1903, Krishan et al. 1885). Among the varieties, the maximum activity of invertase was found in BARI-2 and minimum in BARI-1 at 72 hours of germination.

Upon seed germination, storage proteins are degraded by protease enzymes to provide nutrients for embryo/seedling growth (Bing et al. 2003). The highest protease activity was found in BARI-2 and lowest in BARI-3 at 40 hours of germination while BARI-1 showed the value between the ranges.

Lipases are lipolytic enzymes catalyze the hydrolysis of fats as well as esters of fatty acids with alcohols (Sarda and Desnuelle 1957, Wills 1965). During germination the rapid mobilization of storage triacylglycerols (TAGs) in the cotyledons of seedling require the action of lipases. Of the varieties, BARI-2 should the highest lipase activity and BARI-1 the lowest activity.

From the above result it seems that BARI-2 is a suitable source of amylase, invertase, protease and lipase for purification and characterization.

Total protein and water-soluble protein content of the different varieties of chickpea seeds are presented in Table 2. From the tables, it is found that the chickpea seeds contain a significant amount of protein (total $22.05-22.51 \%$ and water-soluble $15.55-15.68 \%$ ). The results clearly demonstrate that the percentage of both 
types of proteins present in different varieties of chickpea seeds decrease gradually up to 48 hours and then sharply declined up to 144 hours of germination. This indicates that after 96 hours of germination, the proteolytic enzymes may vigorously involve for hydrolysis of seed storage proteins.

Free sugars, particularly glucose, are important in the nervous systems, muscles and many other tissues. Combined with proteins as glycoproteins, the sugars play a role in secretion and external recognition properties of cell membranes. The free sugar contents in three varieties of chickpea seeds are shown in Table 1. During germination, degradation of free sugar in chickpea seed was observed to be rapid.

Reducing sugar contents in three varieties of chickpea seeds are represented in Table 1.. From the table, it was observed that reducing sugar contents in the three varieties of chickpea seed are different. Degradation of reducing sugar at different periods of germination was significant.

One of the nutritional reservoirs in plants, which are used as a fuel, is starch. The starch contents of different varieties of chickpea seeds are shown in Table 1. Starch is the most important polysaccharide in the storage form of carbohydrate in plant. It was found that chickpea seeds contain a large amount of starch 56.00$56.12 \%$. The starch contents of chickpea seeds were found to decrease gradually during germination. In light germination, probably starch first degrades for embryo growth and latter other enzymes utilize seed's storage substance, for the energy supply, required for seedling growth.

The lipid contents of different varieties of chickpea seeds are shown in Table 1. The lipid content was found to degrade quickly up to 48 hours and then gradually up to 144 hours of germination. The decrease in lipid content in the germinating seeds probably caused by the involvement of a lypolytic enzyme, which is responsible for hydrolysis of triacylglycerol that ultimately generate sugars for the growth of germinating embryo. This finding is in good agreement with those reported by Ben et al. (2000).

The seed storage substances gradually decrease with the increase of germination time. The decrease in different types of nutrient content in germinating seeds probably caused by involvement of the hydrolytic enzymes, which hydrolyses seed storage nutrients, a process that generates amino acids and sugars for the development of embryo and seedling growth.

\section{Acknowledgements}

The authors gratefully acknowledge the research and other relevant facilities provided by the Department of Biochemistry and Molecular Biology, University of Rajshahi, Rajshahi-6205, Bangladesh.

\section{References}

Ben Miled D D, Zarrouk M and Cherif A (2000) Sodium chloride effect on lipase activity in germinating seeds. Biochem. Soc. Trans. 28: 899-902

Bing Li Yu, Zhao Min Samuel S M and Sun Jian Liwen (2003) Molecular mechanism of protein degradation upon seed germination. Plant Biology Electronic Abstract Center. Abstract no. 1251

Bligh E G and Dyer W J (1959) Total lipid extraction and purification. Can. J. Biochem. Physiol. 37: 911

Chavan J K, Kadam S S and Salunkhe D K (1986) Biochemistry and technology of chickpea (Cicer arietinum L.) seeds. Crit. Rev. Food Sci. Nutr. 25(2): 107-58

El-Adawy T A (2002) Nutritional composition and antinutritional factors of chickpeas (Cicer arietinum L.) undergoing different cooking methods and germination. Plant Foods Hum Nutr. 57(1): 83-97

Evans D E, Wallace W, Lance R C M and MacLeod L C (1997) Measurement of beta-amylase in malring barley (Hardeum vulgare L). II. The effect of germination and killing. J. Cereal Sci. 26: 241-250 
Geervani P (1991) Utilization of chickpea in India and scope for novel alternative uses, pp. 45-47. In: Uses of Tropical Grain Legumes: Proceedings of consultants' Meeting, March 1989. ICRISAT Center, Patancheru, Andhra Ptadesh, India.

Gupta D K, Tripathi R D, Rai U N, Dwivedi S, Mishra S, Srivastava S and Inouhe M (2007) Changes in amino acid profile and metal content in seeds of Cicer arietinum L. (chickpea) grown under various fly-ash amendments. Chemosphere 66(7): 1382.

Hawkins A and Johnson S K (2005) In vitro carbohydrate digestibility of whole-chickpea and chickpea bread products. Int. J. Food Sci. Nutr. 56(3): 147-55.

Ignacimuthu S and Prakash S (2006) Agro bacterium-mediated transformation of chickpea with alpha-amylase inhibitor gene for insect resistance. J. Biosci. 31(3): 339-345.

Jayaraman J (1985) Laboratory Manual in Biochemistry. Wiley Eastern Ltd., New Delhi, 1st edition.

Kastle J H and Clark M E (1903) On the occurrence of invertase in plants. Amer. J. Chem. 30: 241-245.

Khan M A, Akhtar N, Ullah I and Jaffery S (1995) Nutritional evaluation of Desi and Kabuli chickpeas and their products commonly consumed in Pakistan. Int. J. Food Sci. Nutr. 46(3): 215-223.

Krishan H H B, Blanchette J T and Okita T W (1885) Wheat invertase. Physiol. 78: 241-245.

Kunitz M (1947) Crystalline soybean trypsin inhibitor, J. Gen. Physiol. 30: 291-310.

Lowry O H, Rosenbrough N J and Randall R J (1951) Protein measurement with the Folin-Phenol reagent. J. Boil. Chem. 183: $265-275$.

Mahadevan A and Sridar R (1982) Method in physiological plant pathology. Sivakami publication. Madras. p. 316.

Miller G L (1972) Use of dinitro salicylic acid reagent for determination of reducing sugar. Anal. Chem. 31: 426-428.

Morse E E (1947) Anthrone in estimating low concentration of sucrose. Anal.Chem. 19: 1012-1013.

Nestares T, Barrionuevo M, Urbano G and López-Frias M (1999) Effect of processing methods on the calcium, phosphorus, and phytic acid contents and nutritive utilization of chickpea (Cicer arietinum L.). J. Agric. Food Chem. 47(7): 2807-2812.

Sarda L and Desnuelle P (1957) Sur Quelques Essais be purification de la lipase Pancreatique. BioChem. Biophys. Acta. 50: 515.

Sopanen T and Lauriere C (1989) Release and activity of bound $\beta$-amylase in a germinating barley grain. Plant Physiol. 134: 678-684.

Sugihara A, Shimada Y and Tominaga Y (1990) Separation and characterization of two molecular forms of geotrichum candidum lipase. J. Biochem.107: 426-430.

Suhasini A W and Malleshi N G (2003) Nutritional and carbohydrate characteristics of wheat and chickpea based weaning foods. Int J Food Sci. Nutr. 54(3): 181-7.

Viveros A, Brenes A, Elices R, Arija I and Canales R (2001) Nutritional value of raw and autoclaved kabuli and desi chickpeas (Cicer arietinum L.) for growing chickens. British Poult. Sci. 42(2): 242-51.

WHO (1985) Energy and protein requirements. Report of a joint FAO/WHO/UNU Expert consolation. WHO Tech. Rep. Ser. 724: Geneva, WHO p. 206.

Wills E D (1965) Advanced in Lipid Research. (R. Paoletti and D. Kritchevsky eds.) Academic Press, New York 3: $197-240$.

Wong T (1923) Soybean Industries (I). J. Biol.Chem. 55: 427.

Yamasaki Y (2003) $\beta$-amylase in germinating millet seeds. Phytochem. 64: 935-939. 